Perspective, part of a Special Feature on The Science and Practice of Ecology and Society

\title{
Ecological Conservation, Cultural Preservation, and a Bridge between: the Journey of Shanshui Conservation Center in the Sanjiangyuan Region, Qinghai-Tibetan Plateau, China
}

\author{
$\underline{\text { Xiaoli Shen }}^{l}$ and $\underline{\text { Jiaxin Tan }}^{2}$
}

\begin{abstract}
The Sanjiangyuan region is located on the Qinghai-Tibetan Plateau in western China and encompasses the headwaters of the Yangtze, Yellow and Mekong rivers. It is also home to 300,000 Tibetan pastoralists. The area is characterized by its significant ecological service, unique culture, and fragile ecosystems, and has undergone a rapid degradation over the past several decades. Traditional Tibetan culture offers alternative knowledge and perspectives that facilitate the environmental conservation throughout the region, but have yet to be recognized or adopted by the Chinese government. Beginning in 2007, the local environmental NGO, Shanshui Conservation Center, has initiated a journey to bridge Tibetan communities with the outside scientific community, mainstream society and policy-makers with the aim of advocating integrating traditional Tibetan practices in conservation actions in the Sanjiangyuan region. Through the conservation concession program initiated and facilitated by Shanshui Conservation Center in collaboration with Conservation International, the Sanjiangyuan nature reserve turned over the management of some reserve lands to local communities after a conservation agreement with clear management plans and monitoring indictors was made between the two parties. The trial and demonstration of the conservation concession program successfully led to the adoption of community-based conservation models in state level conservation policy in 2011. We demonstrate as a bridging organization, Shanshui Conservation Center plays the role of cultural translator to promote the understanding and appreciation of traditional Tibetan culture in conservation in western China.
\end{abstract}

Key Words: conservation concession; grassland; traditional ecological knowledge; traditional Tibetan practices; western China

\section{INTRODUCTION}

China is a country that contains incredible globally significant biodiversity. It is also a country with primarily humandominated landscapes that harbor an equally incredible cultural diversity (Edward and Xu 2011). Biodiversity in China has been part of complex historical interactions among biophysical and socio-cultural systems (Sajise 1995). Incorporating the local people and their needs into conservation planning is critical for maintaining biodiversity and the abundance of natural resources in China (Xu et al. 2005).

Nestled within the vast landscape of the Qinghai-Tibetan plateau, is the Sanjiangyuan (meaning three-river headwater) region (Fig. 1). This "Water Tower of Asia" encompasses the headwaters of three of the largest rivers on the continent, the Yangtze, Yellow, and Mekong. These rivers provide 60 billion cubic meters of water annually throughout their reaches (Chen et al. 2007). These headwaters are surrounded by the largest nature reserve in China, the Sanjiangyuan Nature Reserve, established in 2000 with an area of $152,300 \mathrm{~km}^{2}(\mathrm{Li} 2007)$. Sanjiangyuan reserve has the highest concentration of biodiversity and potential ecosystem services of the high altitude regions in the world (QHNEWS 2006). It also provides the largest extent of habitat for the world's most mysterious feline, the snow leopard (Uncia uncia) as well as critical habitat for other endangered species such as wild yak (Bos grunniens), Tibetan wild ass (Equus kiang), and Tibetan antelopes (Pantholops hodgsonii) (Shanshui 2012).

Fig. 1. Location of the Sanjiangyuan region in China (produced by Liu Yanlin)

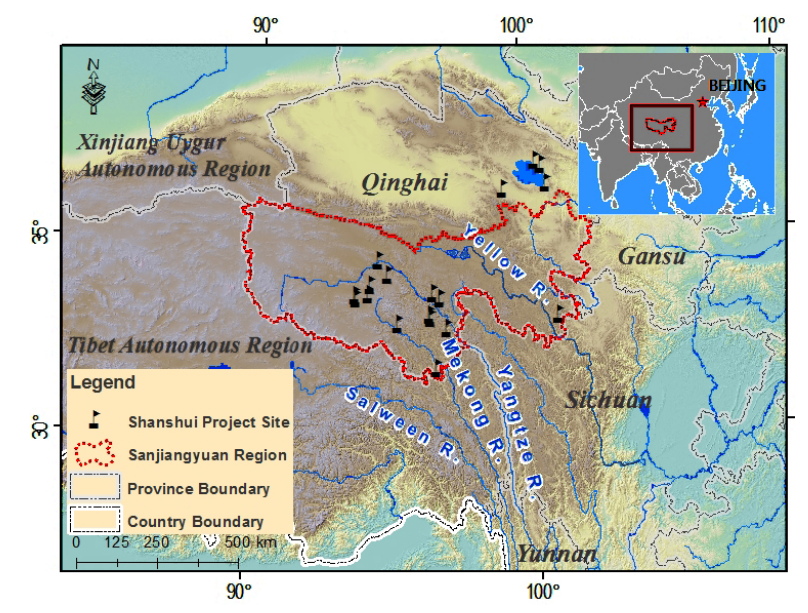


In the Sanjiangyuan region, most of the inhabitants are Tibetan, and follow Tibetan Buddhism, a combination of Bon (a pre-Buddhist religion in Tibet) and Buddhist religion. Tibetans hold a world view where humans are part of an interacting set of living beings and kindness to all creatures earns good karma for oneself (Feng 2005, He 2005). These cultural values encourage a harmonious relationship between humans and nature (Fig. 2). Tibetans do not merely see their rangeland as a commodity to be exploited, but rather as part of a wide-ranging spiritual landscape (Williams 2002). They have effectively protected large regions through their practices of sacred mountain worship (Shen et al. 2012a) and a close relationship between human and wildlife is common in the Tibetan area (Fig. 3). Yet the importance of traditional Tibetan culture in conservation has not been widely recognized. Local people are seldom included in government decisions on conservation and ecosystem management.

Fig. 2. Prayer flags in front of Mt. Namjagbarwa. Tibetans have developed the culture of a sacred landscape. Such cultural values provide the foundation of their faith in protecting nature. (Photo by Lu Zhi)

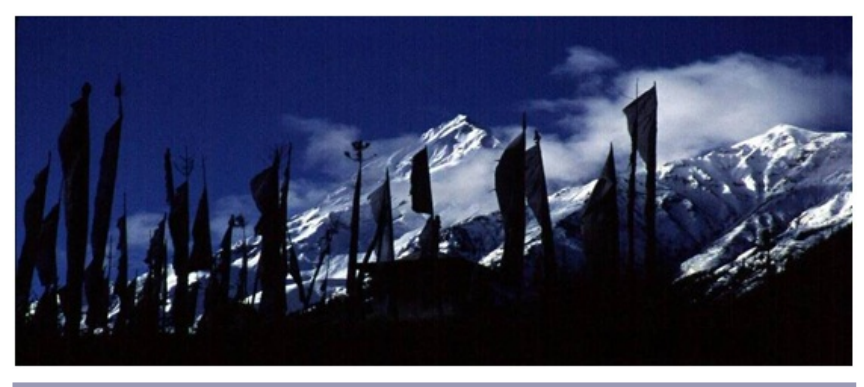

Since its establishment in 2007, the local environmental NGO, Shanshui (meaning mountains and rivers) Conservation Center (henceforth Shanshui), has been engaged in conservation programs throughout the Sanjiangyuan region. In particular, they strive to promote the importance of incorporating local Tibetan people and their culture in conservation. The founding members of Shanshui have extensive experience working on biodiversity conservation in China having worked with the World Wildlife Fund (WWF) and Conservation International (CI). Now, with the intention of focusing on grass-root efforts and reinforcing collaboration with local communities, Dr. Lu Zhi, Shanshui founder and Peking University professor, has taken the initiative to establish this local environmental organization. Shanshui's vision is to strike a balance between maintaining China's natural splendor and achieving local economic development.

Here, we describe three bridge routes found in Shanshui's conservation action plan. These reflect Shanshui's desire to link Tibetan communities with outside society and facilitate the recognition and adoption of Tibetan communities and their culture in conservation action in the Sanjiangyuan region. As a bridging organization, Shanshui provides an arena for exchanging knowledge, building trust, educating, and both vertical and horizontal collaborations (Berkes 2009). Shanshui also serves as a catalyst and facilitator between different levels of government and across resource and knowledge systems (Folke et al. 2005).

\section{THREE BRIDGE ROUTES OF SHANSHUI'S CONSERVATION}

\section{Bridge Route 1: Connect the local Tibetan communities and their traditional ecological knowledge with the scientific community}

When Lu Zhi first visited the Tibetan region, she was inspired by the intimate relationship between local people and wildlife (Fig. 3). The Tibetan region is one of the only remaining places in China to see roaming animals, naive to people. According to the environmental Kuznets curve (Cropper and Griffiths 1994), only when average income reaches a certain point over the course of development can environmental degradation be halted. However, Lu Zhi saw an exception to this rule in the Tibetan region where people highly value the mountains, rivers, trees, and wild animals on their land. Lu Zhi together with other Chinese scholars (Xu et al. 2005) advocated recognizing the conservation value of conventional practices on the basis of traditional cultures and religion in Southwest China. Understanding how traditional Tibetan culture motivates local communities to protect wildlife and the environment has been one key objective of Shanshui and the foundation of its conservation program in the Sanjiangyuan region. Applying these traditional practices to solid program design is a critical step towards implementing sound ecosystem management in the Sanjiangyuan region.

Fig. 3. A red-billed chough (Pyrrhocorax pyrrhocoraxsits) on a Tibetan widow's shoulder. The local people believe that the bird is the reincarnation of the woman's daughter. (Photo by Tashi Duojie)

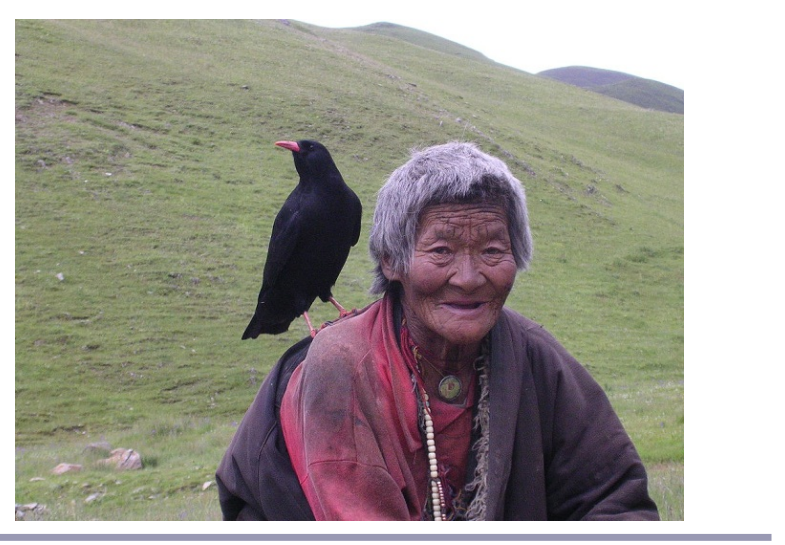


Shanshui has partnered with the Center for Nature and Society of Peking University, to establish scientific research platforms for learning about the current status and changes to critical species and ecosystem, and their relationship with local culture and economy (Shanshui 2012). Shanshui brings together people from different backgrounds, including anthropologists, ecologists, tibetologists, governors, monks, villagers, and graduate students, and encourages extensive and intensive interactions among them. Several studies (Shen et al. 2009, Shen et al. 2012a, Shen et al. 2012b) demonstrate how traditional informal institutions function, the important role of Tibetan sacred mountains in conservation, and the conservation effectiveness of informal institutions as compared to the official conservation network. It was estimated that sacred mountains worshiped and protected by Tibetan people through informal institutions cover a land area equal to all the nature reserves in the Ganzi Tibetan Autonomous Prefecture (Shen et al. 2012a). Tibetan traditional ecological knowledge has a profound effect in raising people's conservation awareness, and has led to a better conservation outcome than government conservation efforts (Shen et al. 2012b).

Another major research endeavor within Sanjiangyuan and other Tibetan regions is the Rapid Biodiversity Assessment Program. It rose from the Rapid Assessment Program of Conservation International which organized a survey in Ganzi Tibetan Autonomous Prefecture, Sichuan Province in 2005 (Alonso et al. 2009). Four global biodiversity hotspots identified by Conservation International (i.e., the mountains of Southeast China, mountains of Central Asia, Eastern Himalaya, and Indo-Burma) (Mittermeier et al. 2004) overlap with the Tibetan region, indicating that the Tibetan region both harbors high biodiversity, as well as severe threats to the biodiversity. Biodiversity information in the Tibetan region is scarce and out of date. In 2007, in collaboration with the Center for Nature and Society of Peking University, Shanshui founded the Rapid Biodiversity Assessment Program aiming at exploring and saving the biodiversity in China. By working through an Eco-Partnership network with more than 40 scientists from different institutions in China and assisted by local specialists, Shanshui has conducted five biodiversity assessments in the remote areas of Sanjiangyuan and other Tibetan regions (Fig. 4). More than 30 new species of plants, rodents, amphibians, and insects have been discovered (Shanshui 2012). Another nine assessments will be conducted in the next three years in the Sanjiangyuan region.

\section{Bridge Route 2: Connect the local community with policy-makers}

Over the past few years, Shanshui has successfully engaged in field and research supported policy initiatives. Through a connection with Dr. Han Qide, the Vice Chairman of the National People's Congress and the President of the Jiu-San Society, a direct communication with the highest leaders in
China was made possible. The Jiu-San Society is a political party featuring members that are high and intermediate level intellectuals in the science and technology fields, and a participating party that accepts the leadership of the Communist Party of China, co-operates with it closely, and dedicates itself to building socialism with Chinese characteristics (JSS 2012). Lu Zhi's involvement in the JiuSan Society and connection with important persons due to her network in Peking University enables Shanshui to discuss conservation action with the state and recommend conservation approaches for the Sanjiangyuan region. Implementing this policy bridge requires much effort and time-investment to understand how Tibetan traditional ecological knowledge promotes conservation, and how it can be integrated within the official nature reserve system. Furthermore, it requires the capacity to develop sound conservation models that fit the Sanjiangyuan region and creatively reflect the local situation to the Chinese state.

Fig. 4. A snow leopard (Uncia uncia) encountered during the rapid biodiversity assessment in the Sanjiangyuan region in the summer of 2012. (Photo by Dong Lei)

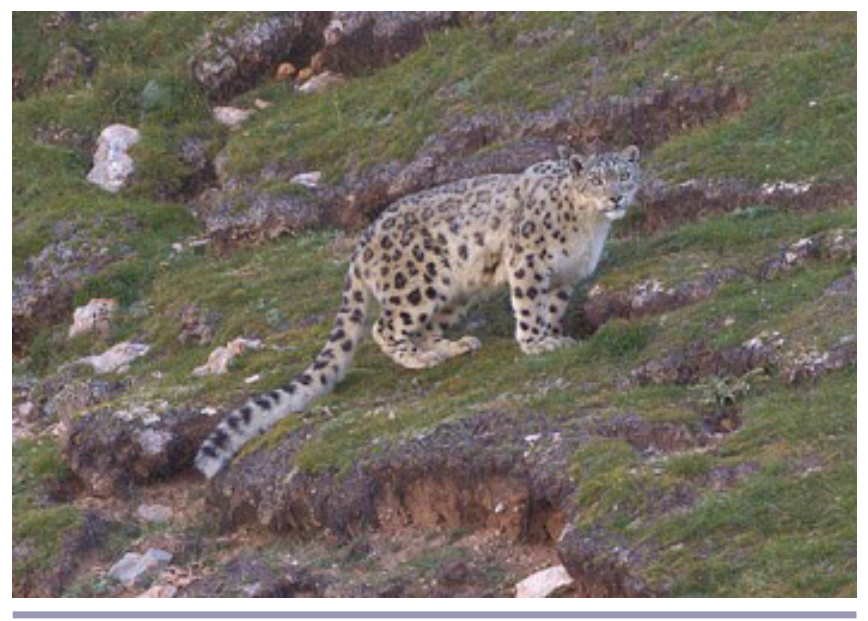

Bridge Route 3: Connect the local community with outside society

Influenced by the rapid socio-economic changes, the youth of Tibetan communities have become insecure and confused about their own cultural identity. They are faced with the cultural dilemma to be 'ordinary' or a minority (Lin 2008). In order to increase their competitiveness in the job market, more young people now prefer to study in school where Mandarin is the teaching language rather than the ethnic school which uses the local minority language as the medium of instruction (Lin 2008). If we believe Tibetan traditions lead to environmental protection, the challenge is to inspire pride of their own tradition in the Tibetan youth (Shen et al. 2012b). Also, the peculiar Tibetan religious and cultural background 
may seem absurd to outside society, and may sometimes be taken as ignorance and superstition. Due to a lack of understanding, Tibetan informal institutions and traditional practices may not be appreciated by mainstream society.

Shanshui is creating various channels to facilitate the interaction between the local community and outside society through tours, public meetings, and publications introducing Tibetan communities, their culture and values. One especially noteworthy accomplishment is the Eye of Community project. The project provided Tibetan villagers video cameras, taught them how to take videos, and then made films based on the stories they recorded. In April 2011, six documentaries (Fig. 5), titled Saddle, Tibetan Butter, Pottery, A gift from Nature, Suoei's Home and the Snow Leopard, and The Yak Dung, produced by the people from the Tibetan communities in the Sanjiangyuan region, were shown in six universities in Beijing. Those films recorded the silent changes that have struck both the nature and culture (Tian 2011), and promote thinking on the role and adaption of traditional Tibetan culture in a changing world. They also attracted the public's attention to Tibetan culture and its connection to local Tibetans' conservation action. Tibetan traditional knowledge provides a useful lens to 'see' and understand the environmental issues. These films challenge a public that is largely beholden to the lens of western science. They provide the awareness that other lenses do exist and an appreciation that they may be the key to collaborations and innovations (Felt 2008). As a consequence, they provided a public platform to better facilitate 'new relationships' between local Tibetans and outsiders, thus generating communication, trust, and a willingness to risk innovative solutions.

Fig. 5. Villagers together with Shanshui staff brought their films to the Yunnan Multi Culture Visual Festival in 2011. (Photo by Lu Bin)

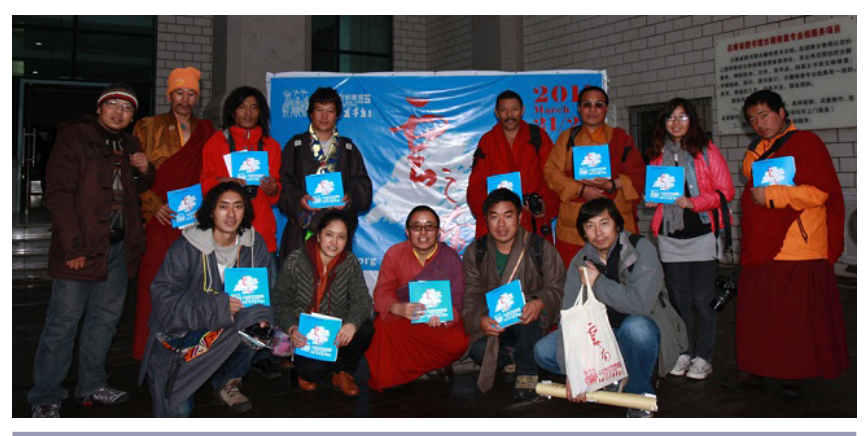

To summarize, we believe Shanshui plays a critical role in facilitating the collaboration and communication among local Tibetan communities, outside science communities, mainstream society, and policy-makers for better ecosystem management and biodiversity conservation in the Sanjiangyuan region. In the next section, we present a specific case study and elaborate how the three bridge routes are reflected in Shanshui's conservation action.

\section{THE CASE STUDY OF SHANSHUI CONSERVATION CENTER - CONSERVATION CONCESSION}

\section{A Tibetan village with strong conservation will}

Cuochi (34.20-34.78N, 93.16-93.93E) village is located in Sanjiangyuan nature reserve with a land area of $2440 \mathrm{~km}^{2}$. The average elevation of the village is $4600 \mathrm{~m}$. It has 301 households and 1039 villagers. Villagers subsist primarily on livestock. In 2010, there were 7928 yaks, 9054 sheep, 1349 goats and 173 horses in the village, a total of 18,504 animals and an average of 61 animals per family. The average income of a family was 5890 RMB (935 USD) in 2010.

Before the Conservation Concession program came to Cuochi, the villagers had been engaged in conservation activities for many years. Cuochi village was built by the Tibetan immigrants in the 1960s and villagers at that time had weak cultural traditions. They hunted wild yaks and marmots for food and fur. Two heavy snow storms (1985 and 1993) greatly decreased the number of livestock, degraded the grassland, and changed the attitude of local villagers toward the environment. They started caring about the environmental changes, and the impact of their activities on the environment. At the same time, the Lama in Ranchang Monastery advocated villagers give up hunting and protect wild animals and grasslands. Buddhist religion and Tibetan traditional practices have been strengthened ever since.

Another reason local villagers are active in conservation is the community education by two NGOs, Plateau Perspective and Upper Yangtze Organization. In 1998, Tashi Duojie, Cuochi native and founder of the first NGO (Upper Yangtze Organization) on the Tibetan plateau, returned to Cuochi and began community education focused on promoting environmental awareness to the villagers. These two NGOs also provided services on health care and education. In 2001 when the village was lacking funds for building the village school, the NGOs helped raise adequate funds. The community education and support worked. In 2002, the village head established a small anti-poaching group of 13 villagers to control illegal hunting by outsiders. At the same time, villagers started formal and regular monitoring of selected wildlife species. In 2004, villagers founded the Friend of Wild Yak Organization that aims to protect wild yaks and other wildlife (Fig. 6).

\section{Empowering local community through Conservation Concession}

Most nature reserves in the Tibetan region are poorly managed because of insufficient staff and financial support (Xie 2004). Sanjiangyuan nature reserve has a land area of $152,300 \mathrm{~km}^{2}$, but has only 13 staff, making it impossible to manage the vast land area. At the same time, local communities with the strong 
desire to protect wildlife and the environment do not have authority to stop outside poachers.

Fig. 6. A local NGO "Friend of Wild Yak Organization" established by Cuochi villagers in 2004. (Photo by Zhala)

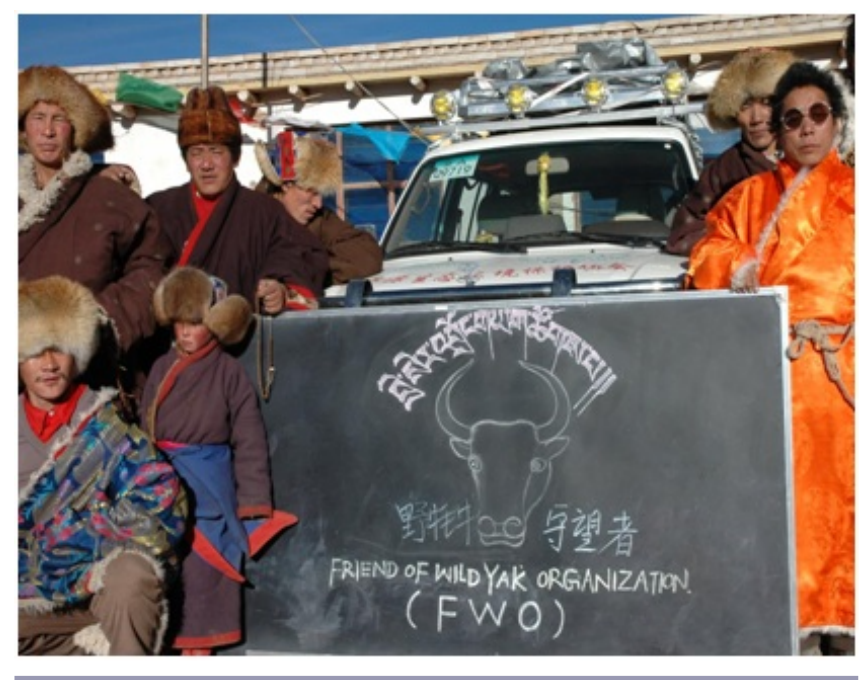

When the new model of Conservation Concession was introduced by Conservation International in 2005, Cuochi was selected as a pilot site based on an awareness of Cuochi's conservation activities and the responsibility of Sanjiangyuan nature reserve. CI supported the first two-year Conservation Concession program, from 1 Oct. 2006 to 30 Sept. 2008. Shortly after in 2007, a group branched off CI and established Shanshui Conservation Center. Shanshui continued a second two-year Conservation Concession program and, in 2010, began scaling up the conservation model in the Sanjiangyuan region in collaboration with $\mathrm{CI}$ and Sanjiangyuan nature reserve. When the Conservation Concession agreement was signed between the bureau of Sangjiangyuan nature reserve and Karma, the village head in 2006, Karma's exuberant response (below) demonstrates why the villagers greatly cherished the conservation rights authorized by the government.

\section{I am so excited about the agreement signed between the bureau of Sanjiangyuan nature reserve and my village. We nomads live on our livestock, yaks, goats, and horses. Our life heavily relies on the grassland. We benefit directly from protection of the grassland. We are excited to have our sacred mountain under legal protection. The sacred mountain is our spiritual home. In such a changing world, we feel secure when we can protect and keep our home land, the source of our identity, as it was.}

Through the agreement, Sanjiangyuan reserve handed over the management rights of Cuochi village to its villagers. The agreement includes the following contents: 1) Cuochi villagers are authorized to protect the land in which they traditionally dwell, which includes their sacred mountain (Fig. 7); 2) Cuochi villagers are responsible for conservation activities such as patrolling, wildlife monitoring, and environmental education; 3) capacity building for the villagers is provided by $\mathrm{CI} /$ Shanshui, and an annual award of 20,000 RMB (3170 USD) for conservation activities is provided by the bureau of Sanjiangyuan nature reserve. In exchange for carrying out management responsibilities, villagers received a satellite phone (Cuochi's only form of communication), health care, and electric fencing to protect their houses from brown bear (Ursus arctos) attack in winter pastures when they move to summer pastures.

Fig. 7. Community patrols by Cuochi villagers. (Photo by Shanshui)

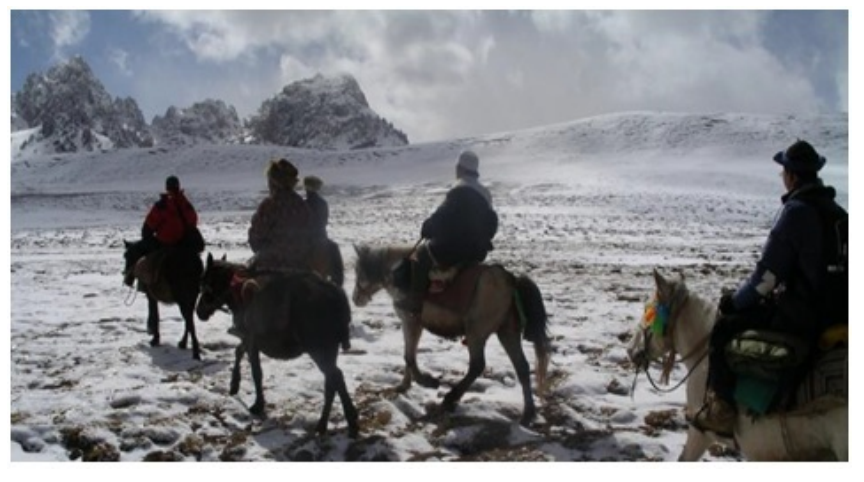

The program has several key stages including a feasibility study, signing of conservation contracts, transfer of legal management rights to local communities, implementation of contracts, and final project evaluation (Foggin 2011). Cuochi villagers effectively carried out the duties entrusted to them (Fig. 8). Even during the intermission of two Conservation Concession programs, from late 2008 to early 2010, the villagers continued their conservation activities. From 2006 to 2010 they achieved the following: 1) set up 13 wildlife conservation areas, two headwater conservation areas, and three no-grazing areas; 2) stopped five violation events (four poaching and one illegal mining); 3) five households volunteered to give up grazing in five wildlife core zones and three migratory corridors (see details below); 4) conducted wildlife and phenological/climate monitoring (i.e., changes in snow lines, and blooming times of flora species); 5) added environmental education into the annual cultural festival; and 6) developed village folk regulations that integrated conservation into the village's daily activities.

Shanshui field scientist, Liu Yanlin, described the resettlement of five households for conserving wild yak (achievement 3 above) and how, when given full autonomy to conserve 
wildlife and protect the environment, local communities have the capacity to make their own decisions and adjust their activities to meet the conservation goals.

Fig. 8. Community members display their conservation commitments and the benefits they receive through the Conservation Concession program. (Photo by Shanshui)

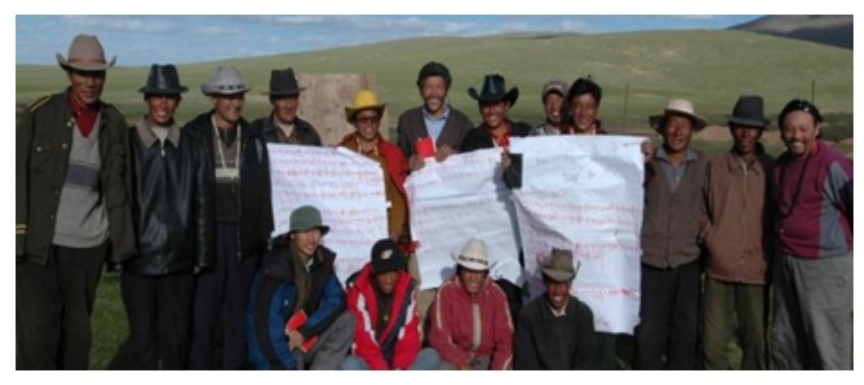

There was a small population of wild yaks living at an area called Kehuobai in southern Cuochi. A total of 55 wild yaks were observed during the community monitoring in 2005. Five herder families living in this area worried that the grazing of livestock probably degraded the grassland, as they saw the wild yaks less often. They came to Friend of Wild Yak Organization, expressed their worries and discussed how they could bring those animals back to Kehuobai. The five families decided to move out of the area with their livestock in 2006. What was unexpected is that in the following years, during the wildlife monitoring the villagers found the wild yaks had completely abandoned this area. One reason for this, they believed, was because poachers came into the area after local people moved out, as supported by several encounters during the routine patrolling. Also, villagers found the grass turned older and tougher without livestock grazing and disturbance, which they thought might be another reason. After consulting with the Friend of Wild Yak Organization, three of the five families moved back to Kehuobai in 2012.

\section{From threats to allies}

The grasslands in the Sanjiangyuan region have undergone rapid degradation over the past several decades. More than half of the rangelands are moderately to severely degraded (Wang et al. 2001). Soil erosion has deteriorated about 26.5\% of the region's total land area (Wang et al. 2001). The number of days the river is dry is increasing ( $\mathrm{Lu} \mathrm{2007).} \mathrm{The} \mathrm{average}$ annual runoff decreased more than $20 \%$ during the last 50 years (Qinghai Provincial Government 2005). The environmental degradation has negatively impacted the livelihood of local Tibetan communities and caused economic losses. Conservation of the Sanjiangyuan region has been a great concern of the country for ecological, social, and economic reasons.

In 2005, the government initiated the Ecological Protection and Restoration Program to curb the rapid grassland degradation in the Sanjiangyuan region. One action of the program was called "Ecological Migration", which relocated people from the Sanjiangyuan reserve into newly created towns by providing housing and compensation for the restoration of the degraded grassland. This program was unprecedented in scale and extent. A total of 1.5 billion RMB (about 230 million USD) was allocated for resettlement, aimed at relocating 100,000 local herders by the end of the program in 2010. Taking Cuochi as an example, from 2006 to 2011, 43 households signed a 10-year agreement with government, sold their livestock, and moved to Ge'ermu city. Each household was given a house of 80 square meters and a subsistence allowance of 8000 RMB (1270 USD) per year. There have been debates whether the translocation has achieved its desired ecological goals. A criticism of the program is its unexpected social impacts. The drastic changes from traditional pastoral livelihoods to urban life change the community structure, sometimes lead to high levels of unemployment, and the loss of hope and culture (Foggin and Torrance-Foggin 2011).

The underlying assumption of the Ecological Migration program was that the activity of local communities was one of the main causes of grassland degradation. Local people were treated as threats to conservation. Relocating the people out of the reserve was a simple and crude strategy that has precedence throughout the world. However, the history of living in this high grassland for centuries suggests that local communities have accumulated rich experience in adapting and surviving in the very harsh and fragile environment. Their traditional ecological knowledge and practices should be respected. The Cuochi village Conservation Concession demonstrates, when incorporated into the formal conservation network, local communities can be excellent allies to achieve local and regional conservation goals.

The key for the sustainability of Conservation Concession in Tibetan area is the continuation of local community's conservation rights. Based on Shanshui's experiences, the nature reserves and local governments which are responsible for conservation, and the local communities which have a deep-rooted culture of protecting land and lives, share a common interest and may achieve conservation agreement with proper facilitation. With the commitment of key stakeholders, and with sufficient time allowed for trust and understanding to develop, it is possible for the collaborative management to be developed (Foggin and Torrance-Foggin 2011). Encouraged by the Cuochi example, several neighboring villages formed their own conservation associations. Following the success at Cuochi, Sanjiangyuan nature reserve plans to scale up the new conservation model throughout the reserve. Currently, the reserve has signed Conservation Concession agreements with three other Tibetan villages; one assisted by Shanshui and two independently developed by the reserve itself. 


\section{Conservation on the move}

Dr. Han Qide has been a key figure in pushing forward the Sanjiangyuan conservation with Shanshui since 2007. In 2010, Han Qide and officials from relevant ministries travelled to the Sanjiangyuan region. In April 2011, a two-day forum, The New Hope in Sanjiangyuan, was held in Peking University by the Jiu-San Society, Qinghai Provincial CPC (Communist Party of China) Committee, The People's government of Yushu Prefecture, Center for Nature and Society of Peking University, and Shanshui Conservation Center. The forum brought together governors from the state and Qinghai province, scholars, conservationists, and village representatives from the Sanjiangyuan region. The participants reviewed the conservation issues and government conservation efforts in the Sanjiangyuan region, shared the experience and lessons learned from the Conservation Concession program, and discussed possible conservation models for the region. It sent the message that the Conservation Concession approach is relatively cost effective and could serve as a way to adapt traditional institutions to complement the official conservation network in the Tibetan region. Following the forum, in June 2011, a letter prepared by Shanshui was sent to the national leaders in name of the Jiu-San Society recommending that government recognize the contribution of Tibetan traditional practices in conservation, and encourage and purchase the conservation services provided by local communities through Conservation Concession as a new conservation approach in the Sanjiangyuan region.

In November 2011, the Executive Meetings of the State Council approved the implementation of the "Overall Integrated Test Program for State Ecological Protection in the Sanjiangyuan region in Qinghai" to curb the degradation of ecological functions of the Sanjiangyuan region and explore the establishment of eco-building and institutional mechanisms for environmental protection. There are two points in the statement worth noticing:

1. Establish a standard long-term ecological compensation mechanism and be innovative with institutional mechanisms for ecological protection. Set up public welfare positions for ecological management and protection with farmers and herdsmen playing a major role in ecological protection.

2. Encourage and guide individuals, private organizations, and social organizations to actively support and participate in Sanjiangyuan ecological protection charities.

This is the first time that the state conservation policy emphasized the important role of local Tibetan communities and social sectors in conservation in the Sanjiangyuan region. It is a positive message which shows the state's increased interest in and motivation for collaborative management in conservation. We think Shanshui plays a critical role in the transition towards a community-based approach for conservation and ecosystem management in the Sanjiangyuan region through its active innovation and demonstration of conservation models and by connecting the Tibetan community with the government.

\section{DISCUSION}

Since its establishment in 2007, Shanshui has endeavored to explore a community-based conservation approach in the Sanjiangyuan region. Throughout this process, institutional innovation, initiated at the rural grassroots level, played a critical role in the implementation of this community-based approach. Considering the Cuoci village, Conservation Concession is a strong representation of institutional innovation, and the crucial role of communities in effective reserve management. This collaborative project in turn has reinforced communication and trust leading to increased commitment to conservation by the local Tibetans, and increased acknowledgement of this model for environmental protection by the government. Conservation Concession is a way to include local communities in comanagement of the reserves (CI 2012), and helps to increase efficiency while reducing costs.

In this complex process of institutional change, Shanshui's experiences show that an organization that plays a bridging role is critical to facilitating the institutional experiments. Shanshui facilitates the communication and interaction among local villagers, the Bureau of Sanjiangyuan nature reserve, and policy makers by creating a range of opportunities for formal and informal interactions and providing an arena for vertical and horizontal collaboration. Most importantly, Shanshui provides a philosophy among different stakeholders that respects the local people and values their traditional practices. In addition, Shanshui's bridging role and its leadership are key factors that enable a comanagement system to deal with knowledge issues (Berkes 2009), especially in a context where Tibetan traditional ecological knowledge is based on a different epistemology and worldview (affected by the local belief systems of Tibetan Buddhism) from western science.

Nevertheless, integrating Tibetan traditional ecological knowledge with western science for conservation is challenging. Connecting this to Max-Neef's (2005) claims on the dichotomy between western and eastern culture, we believe that some policy-makers and scientists see the Tibetan traditional practices, as mysterious, sometimes irrational, and seldom as efficient and competent as the scientific ecological knowledge. In other words, they do not trust local knowledge. To promote an appreciation of Tibetan traditional ecological knowledge to policy makers, Shanshui plays the role of cultural translator. As Yang (2010) points out, cultural translation has become a new feature of environmental activism of NGOs in China. This feature requires considerable effort to first understand the source language and culture in 
the local context, and then to creatively reflect the local situation to the state. For Shanshui, this means a large time investment for interactions with the local villagers, and indepth research to understand how traditional Tibetan culture drives the strong conservation ethic of local communities. The next challenging step is to translate this 'source language' to the policy makers. The collaboration with the Jiu-San Society creates an opportunity for Shanshui to open a dialogue and submit conservation proposals to the top leadership of Chinese government.

\section{CONCLUSION}

We advocate a community-based approach to incorporate Tibetan traditional practices into official conservation network in the Sanjiangyuan region. The acceptance of Tibetan traditional ecological knowledge in conservation is limited and still in the early stages of development. To further its engagement in ecosystem management, there is a critical need for the nurturing of traditional and collaborative stewardship systems. This in turn will protect, restore, and enhance the productivity, diversity, and resilience of critical ecosystems (Thornton 2012) and sustain the balance between ecosystem services and human well-being. In this light, the pioneering program of Conservation Concession initiated by Shanshui in the Sanjiangyuan region shows that we have the opportunities to maintain human well-being by working handin-hand with the local community. A stronger recognition of the relationship between ecological protection and cultural preservation in the Sanjiangyuan region will improve future ecosystem management and cultural preservation. This is because successful management cannot occur without the recognition that local Tibetans and their traditional practices and culture are very much part of the conservation process. In this sense, resource management of any type is essentially about finding ways to allow sustainable management while protecting, even enhancing, the lifestyles and cultures of those who harvest and use the resources (Felt 2008).

Responses to this article can be read online at: http://www.ecologyandsociety.org/issues/responses. php/5345

\section{Acknowledgments:}

We acknowledge Lu Zhi, Sun Shan, Liu Yanlin, Song Ruilinng and Zhu Yingying who provided information about Shanshui Conservation Center and its projects in the Sanjiangyuan region, which was important for writing this article. We thank Byron Weckworth who greatly helped to improve the English writing of this article. We note that both authors contribute equally to this essay.

\section{LITERATURE CITED}

Alonso, L. E., S. Liu, X. Shen, and J. McCullough. 2009. A Rapid Biological Assessment of three sites in the Mountains of Southwest China Hotspot, Ganzi Prefecture, Sichuan Province, China (RAP Bulletin of Biological Assessment 52). Conservation International, Arlington, VA, USA.

Berkes, F. 2009. Evolution of co-management: role of knowledge generation, bridging organisations and social learning. Journal of Environmental Management 90: 1692-1702. http://dx.doi.org/10.1016/j.jenvman.2008.12.001

The Central Committee of the Jiu-San Society (JSS). 2012. Rule. [online] URL: http://www.93.gov.cn/contact/index. $\underline{\text { shtml }}$

Chen, G., X. Li, and X. Guo. 2007. Ecological Protection and Construction in Sanjiangyuan Nature Reserve. Qinghai People's Press, Qinghai, China.

Conservation International (CI). 2011. Conservation Stewards Program - Tibetan Plateau, China. [online] URL: http://www. conservation.org/global/csp/Documents/CSP_SNNR_FS_FINAL. pdf

Cropper, M., and C. Griffiths. 1994. The interaction of population growth and environmental quality. American Economic Review 84: 250-254.

Edward, G. R., and J. Xu. 2011. Creating a 'Conservation with Chinese Characteristics'. Biological Conservation 144: 1347-1355. http://dx.doi.org/10.1016/j.biocon.2011.03.006

Felt, L. 2008. It all depends on the lens, B'y: local ecological knowledge and institutional science in an expanding finfish aquaculture sector. Pages 167-190 in K. Culver, and D. Castle, editors. Aquaculture, innovation and social transformation. The International Library of Environmental, Agricultural and Food Ethics 17, Springer Science and Business Media. http:// dx.doi.org/10.1007/978-1-4020-8835-3_11

Feng, Z. 2005. The conservation perspective of Tibetan Buddhism. Pages 83-89 in J. Z. Ma, and J. Chen, editors. Tibetan Culture and Biodiversity Conservation. Yunnan Science and Technology Press, Yunnan, China.

Foggin, J. M. 2011. Local Communities and Conservation on the Tibetan Plateau: Two case studies of collaborative management in the Sanjiangyuan region. Pages 50-60 in Selection of presentations from the international symposium on the "human dimensions of ecological conservation in the Tibetan plateau region". Qinghai, China.

Foggin, J. M., and M. E. Torrance-Foggin. 2011. How can social and environmental services be provided for mobile Tibetan herders? Collaborative examples from Qinghai Province, China. Pastoralism: Research, Policy and Practice 1:1, 21 http://dx.doi.org/10.1186/2041-7136-1-21 
Folke, C., T. Hahn, P. Olsson, and J. Norberg. 2005. Adaptive governance of socialecological systems. Annual Review of Environment and Resources 30: 441-473. http://dx.doi. org/10.1146/annurev.energy.30.050504.144511

He, J. H. 2005. The role of Tibetan Bon religion in conservation. Pages 68-72 in J. Z. Ma, and J. Chen, editors. Tibetan Culture and Biodiversity Conservation. Yunnan Science and Technology Press, Yunnan, China.

Li, Y., 2007. Policy Options on Sustainability in the Three River Sources Region of the Qinghai-Tibet Plateau. Qinghai People's Press, Xining, China.

Lin, Y., 2008. Cultural Exclusion in China: State Education, Social Mobility and Cultural Difference. Routledge, New York, USA.

Lu, B., 2007. The Yangtze River is facing threat of drought. http://news.163.com/07/1116/09/3TDMJLTN00011SM92.html (in Chinese).

Max-Neef, M. A. 2005. Foundations of transdisciplinarity. Ecological Economics 53: 5-16. http://dx.doi.org/10.1016/j. ecolecon.2005.01.014

Mittermeier, R. A., P. R. Gil, M. Hoffmann, J. Pilgrim, T. Brooks, C. G. Mittermeier, J. Lamoreux, and G. A. B. da Fonseca. 2004. Hotspots revisited. CEMEX, Mexico.

Nan, W. Y. 2001. The taboos in Tibetan areas and the role they have played in environmental protection. North West Minorities Research 3, 21-29.

Qinghai Provincial Government. 2005. Seven point five billion to protect the Sanjiangyuan region. http://epaper.tibet3. com/qhrb/html/2009-03/ 20/node_11.htm (in Chinese).

Qinghai News (QHNEWS). 2006. Four Striking Characteristics of the Sanjiangyuan Nature Reserve. [online] URL: http://www.qhnews.com/sjy/system/2006/09/29/000005511. $\underline{\text { shtml }}$

Sajise, P. E. 1995. Biodiversity and methods: a synthesis. Pages 277-281 in S. J. Pei and P. E. Sajise, editors. Regional study on biodiveristy: concepts, frameworks. Yunnan University Press Kunming, China.

Shanshui Conservation Center (Shanshui). 2012. Source of Three Rivers [online] URL: http://www.shanshui.org/ Landscape/Project/buss/

Shen, X. L., S. Z. Li, F. Tian, and Z. Lu. 2007. A new approach to conservation in western China. Pages 193-215 in Institute of Environment and Development, China Academy of Social Sciences, editor. China environment and development review Vol. 3. Social Sciences Academic Press, Beijing, China.

Shen, X., Z. Lu, S. Li, and N. Chen. 2012a. Tibetan sacred sites: understanding the traditional management system and its role in modern conservation. Ecology and Society 17(2): 13. http://dx.doi.org/10.5751/ES-04785-170213

Shen, X., S. Li, N. Chen, S. Li, W. J. Mcshea and Z. Lu. $2012 b$. Does science replace traditions? Correlates between traditional Tibetan culture and local bird diversity in Southwest China. Biological Conservation 145: 160-170. http://dx.doi.org/10.1016/j.biocon.2011.10.027

Thornton, T. F. and A. M. Scheer. 2012. Collaborative Engagement of Local and Traditional Knowledge and Science in Marine Environments: A Review. Ecology and Society 17 (3):8. http://dx.doi.org/10.5751/ES-04714-170308

Tian, Z. 2011. The stories told by Tibetan people. Nanfang Daily, 2011-05-10, p.B16. (in Chinese)

Wang, Z. M., K. S. Song, and L. J. Hu. 2010. China's largest scale ecological migration in the three-river headwater region. AMBIO: A Journal of the Human Environment 39(5-6): 443446.

Williams, D. M. 2002. Beyond Great Walls: Environment, Identity, and Development on the Chinese Grasslands of Inner Mongolia. Stanford University Press, Stanford, California, USA.

Xie, Y. 2004. Review on the management system of China's nature reserves. Pages 33-51 in Y. Xie, S. Wang, and S. Peter, editors. China's protected areas. Tsinghua University Press, Beijing, China.

Xu, J., E. T. Ma, D. Tashi, Y. Fu, Z. Lu, and D. Melick. 2005. Integrating sacred knowledge for conservation: cultures and landscapes in southwest China. Ecology and Society 10(2):7. [online] URL: http://www.ecologyandsociety.org/vol10/iss2/ $\underline{\operatorname{art} 7}$

Yang, G. 2010. Civic environmentalism. Pages 119-139 in Y.T. Hsing and C. K. Lee, editors. Reclaming Chinese Society: The new social activism. Routledge, London, UK. 